\title{
Trading With A Day Job: Can Automated Trading Strategies Be Profitable?
}

Robert W. Stone, (E-mail: rstone@uidaho.edu), University of Idaho R. Ashley Lyman, University of Idaho

\begin{abstract}
The focus of the research is the profitability of using automated trading strategies. In other words, can trading strategies that are automatically executed in financial markets be profitable? In this study, three strategies are traded in a simulated environment under two different types of market conditions and on two different underlying assets. The trading strategies are based on a moving average crossover system with 5, 10, and 20 day moving averages. The first strategy uses only this moving average crossover system. The second strategy uses this same moving average system requiring increasing volume confirmation to make a trade. The final strategy uses this moving average crossover system but requires confirmation by a relative strength index to make a trade. The two market conditions used are an upward trending market and a consolidating market. The assets traded are the NASDQ 100 (i.e., QQQQ) and the $S \& P$ Deposit Receipts Trust (SPY). These assets tend to have different levels of volatility over time.
\end{abstract}

The automated trading strategies are simulated using historical data and the trading software TradeStation. TradeStation allows for trading strategies to be implemented and tested on historic data at various time intervals and using a variety of time charts. A number of numeric values are also calculated by TradeStation including the number of trades and the profit or loss produced by these trades. The simulation results indicated that for both assets in markets that trend upwards, the moving average strategy with confirmation by the relative strength index dominated the other two strategies in terms of profits. During consolidating market periods, the simulation results are less clear. The magnitude of the profits when trading the relatively stable $S \& P$ varied across the three strategies and various time charts. However for the more volatile NASDQ 100, profits tended to be greater for the simple moving average strategy than the other two strategies.

\section{INTRODUCTION}

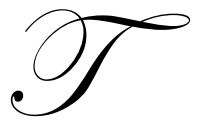

he trading of derivatives in financial markets is popular in corporations. It has been reported that 92\% of the world's 500 largest corporations trade derivatives. (Smithson and Simkins, 2005). These corporations employ professional traders who spend their corporate careers trading derivatives for financial risk management (Smithson and Simkins, 2005). While some researchers have concluded that firms trading for risk management receive little risk reduction (Hentschel and Kothari, 2001), others have found these activities to add value to the firm (Smithson and Simkins, 2005). The trading of derivatives is also done for speculation purposes and can be profitable through the exploitation of information and cost advantages (Geczy, Minton, Schrand, 2005). The growth in derivative trading has not only provided opportunities for productive activities such as risk management and speculation, but it has also provided opportunities for destructive activities, including fraud and manipulation (Dodd, 2004).

While the above discussion focuses on professional traders, there are also individual investors and traders of derivatives who are not professional traders. These non-professional traders are individuals for whom trading is not their primary vocation and thus they depend on another, non-trading source of income. Trading in financial markets is a financial sideline or hobby for this trader. In other words, this type of trader has a day job. Unlike the trading professional, this trader cannot devote all their work time and efforts to trading. Their trading strategies are 
constrained by the lack of trader time and energy focus to strategy development, execution, and monitoring. It is this group of traders upon which this research is focused.

On a theoretical level, it has been shown that there are incentives for individuals to hold derivatives in an investment portfolio (Carr and Madan, 2001). Furthermore, for individual investors who are uninformed, it is rational for them to be followers of market trends while better informed investors benefit from a contrarian strategy (Brennan and Cao, 1996). For the more active traders, even the non-professional trader, the basic trading strategies are limited by the need to pay attention to the trader's day job. This constraint limits the attention that can be paid to any trading strategy and to the positions created by strategies. The basic approaches for these investors can be classified in two groups. The first group contains longer term strategies which require less day to day attention and energy from the trader. The downside to these strategies is that they have limited ability to generate regular returns due to their long term nature and the lack of attention paid to monitor and adjust the trading position to market conditions. The second group is to develop and execute strategies only when the individual trader has time to monitor and implement these strategies. When the time demands of their other job keeps the trader from appropriately monitoring and adjusting their trading strategy, the trader exits the positions and leaves the market. The difficulty with this approach is that strategies may often require more time to "play out" in the market in order to be profitable. Furthermore, the opportunities appropriate for the execution of a strategy would be greatly limited in this environment.

The purpose of this research is to examine the viability of automating the implementation of trading strategies in financial derivative markets. The ultimate goal is to determine if the automation of appropriate trading strategies can be profitable. If so, the individual trader who does not trade as a full time vocation or avocation may well be able to successfully trade while keeping their day job. In essence, this would allow the identification of a viable trading method beyond the two groups discussed above. The research presented below begins with a review of the literature appropriate for derivative trading and the automation of trading strategies. The empirical method employed is to simulate three trading strategies on historic data using an automated trading feature in a trading software program. Two different exchanged traded funds are used, one tending to be more volatile than the other. The time periods used included a time when both assets are trending upward and another time period when each asset is consolidating. The simulations are designed to examine several features of these strategies including profitability and the number of trades. Based on these simulations, results are presented about the efficacy and ultimately the profitability of these trading strategies in an automated setting. From these simulation results conclusions are provided.

\section{THE LITERATURE}

Traders analyze markets by examining fundamentals and technical indicators (Oberlechner, 2001). Practicing foreign exchange traders rely more heavily on technical analysis while financial journalists believe that fundamental analysis is more important (Oberlechner, 2001). Regardless of the approach used, successful traders adapt to market conditions, dropping strategies when they become losers and searching for more profitable ones (Dempster and Jones, 2001). The ultimate goal for any trader using any strategy in any market is to make a profit (Gencay, 1997).

Studies performed to examine the effectiveness of various trading approaches (e.g., fundamental analysis, technical analysis, adapting to markets) have not provided a definitive answer on superiority. Some studies have shown that economic variables, the basis of fundamental analysis, are unimportant in producing trading profits compared to technical analysis and indicators (Austin, Bates, Dempster, Leemans, and Williams, 2004). The adaptive approach to adjusting trading methods based on market conditions and what "works" has also been shown to perform modestly better than not adjusting to the market (Dempster and Jones, 2001). In the equities market, the strategy of using fundamental analysis to select, buy, and hold equities has been shown inferior, in terms of profit creation, to using technical indicators to trade equities based on market conditions (Gencay, 1997).

The search for profits from trading activities leads to the continual assessment of trading strategies and methods. As mentioned above, professional traders, who spend their working careers studying markets in which they develop, execute, monitor, and adapt trading strategies are able to devote significant time and energy to trading. 
However, the individual who is not a professional trader does not necessarily have such time and energy to commit to trading. These individuals, who have day jobs, have the difficult task of balancing their day jobs while pursuing trading strategies. One approach for the trader with a day job is to use fundamental analysis to select good (i.e., potentially profitable) securities to buy or sell long term and use technical analysis to identify a good price to enter as well as to exit the market. In this fashion their position requires little time that must be "found" along with their other responsibilities. However, this strategy has been shown to not be as profitable as pursuing strategies using more time consumptive technical trading strategies (Austin, Bates, Dempster, Leemans, and Williams, 2004).

Another potential approach for trading with a day job is to automate the trading strategies used. This means programming the selected trading strategy into a trading platform and allowing the software to execute trades in response to market conditions. An approach in this vein is to develop software agents that monitor the financial markets on live data feeds and alert the human trading when action is required (Ash, 2004). A more technical approach to automated trading is to define the strategy and agents so that any required actions are executed by the software. Not only are such systems possible, these have been shown to be comparable in profitability to systems requiring the human trader to execute trades (Subramanian, Ramamoorthy, Stone, and Kuipers, 2006).

\section{THE METHOD}

The profitability and characteristics of automated trading strategies were studied using simulation done in the trading software TradeStation. This software is a trading platform which allows trading strategies to be automated and tested on a variety of financial instruments using historic data. Two exchange traded funds were studied, the NASDAQ 100 (QQQQ) and the S\&P Deposit Receipts Trust (SPY). These were selected for their high degree of liquidity as well as to represent two assets with different levels of market volatility. In general, the QQQQ tends to display more volatility than the SPY. These funds were also studied over two different time periods, one when both funds were consolidating and the other when they were both trending upwards. These time periods were from March 15, 1999 to June 15, 1999 for a consolidating market and from January 3, 2005 to December 30, 2005 for an upward trending market. Figure 1 illustrates the daily values for both the SPY and QQQQ during the consolidating market period. Figure 2 illustrates both these daily markets during the upward trending time periods. During both times periods, different length time charts were used for the basis of trading. That is, the strategies and the resulting automated trades were performed on daily, 60 minute, 30 minute, 15 minute, 5 minute, and 1 minute time charts. Using the different length time charts allows the examination of strategy frequency on profitability.

The structure of the trading scenario created for the simulations had several dimensions. First, the trading account had $\$ 100,000$ in initial capital. No transaction costs were recorded on any trades and the trade size was fixed at 100 shares or contracts. Three strategies were tested, all based on a moving average crossover system using three moving averages, a five day, a ten day, and a twenty day. In this system, a buy signal is generated when the five day moving average is greater than the ten day and the ten day is greater than the twenty day moving average. A sell signal is generated when the reverse is true (i.e., the twenty day moving average is greater than the ten day and the ten day greater than the five day moving average).

The first simulated trading strategy used only the moving average system to make long and short market entries and to close open positions. The other two strategies refined this moving average system by adding a confirming signal. The second strategy added increasing volume as a confirming indicator to buy and sell signals from the moving average system. In other words, a signal to trade from the moving average system required confirmation by increasing volume in order for the trades to be executed. The final strategy added to the moving average system a signal from the relative strength index (RSI) as confirmation. The RSI is an index ranging from 0 to 100 which uses the ratio of average of X-day closes that are up from the opening divided by the average of X-day closes that are down from the opening. If the RSI is 70 or greater it signals that the market is overbought and that closing long positions and selling short are appropriate trades. If the RSI is 30 or less it signals that the market is oversold and indicates to close short positions and to enter long positions. For this third strategy, like the second, the moving average signals must be confirmed by the RSI before a trade is made. 
Figure 1

The Consolidating Markets

SPY: Daily

March 15, 1999 to June 15, 1999

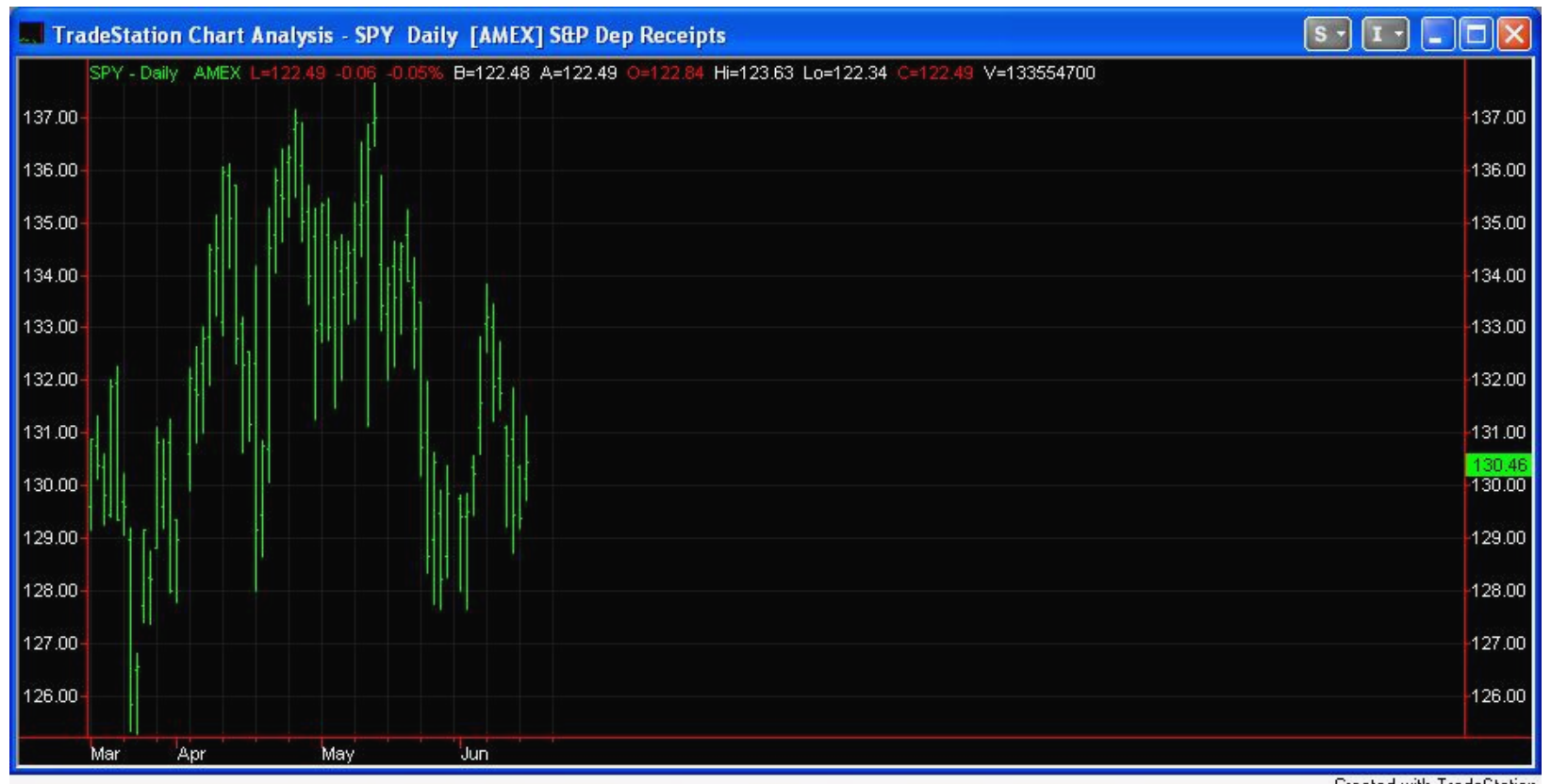

Created with TradeStation

QQQQ: Daily

March 15, 1999 to June 15, 1999

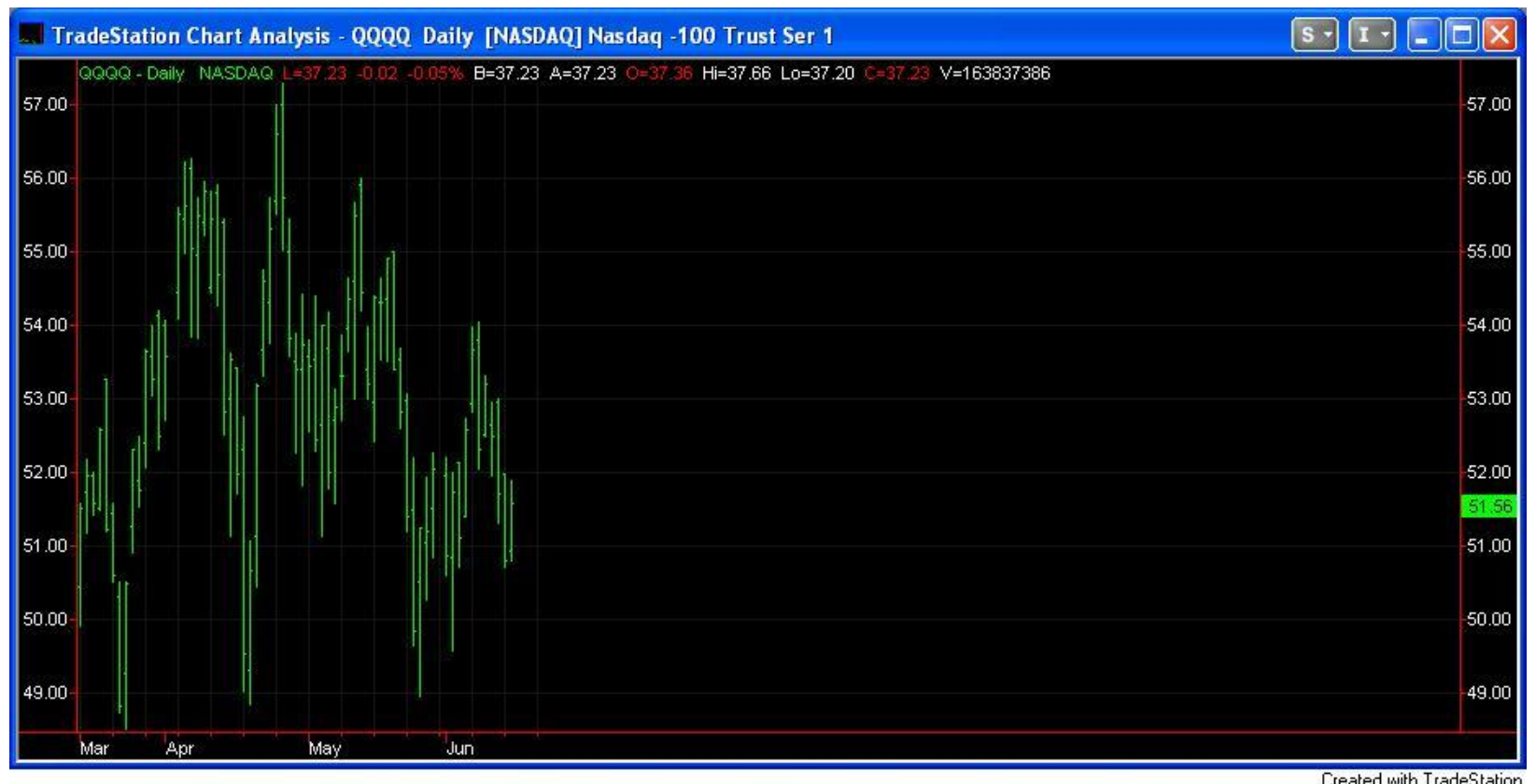

Created with TradeStation 
Figure 2

The Upward Trend Markets

SPY: Daily

January 1, 2005 to December 30, 2005

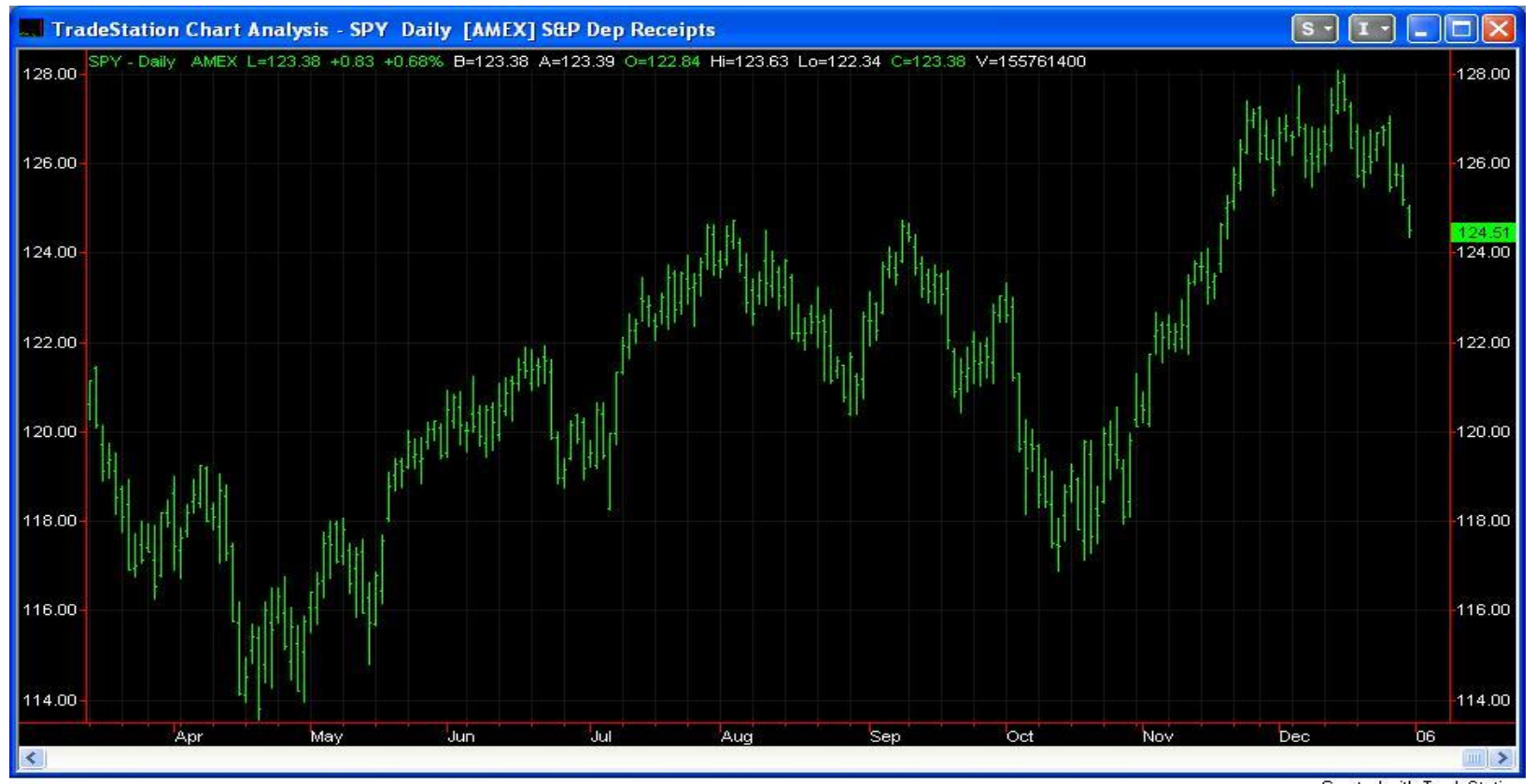

Created with TradeStation

QQQQ: Daily

January 1, 2005 to December 30, 2005

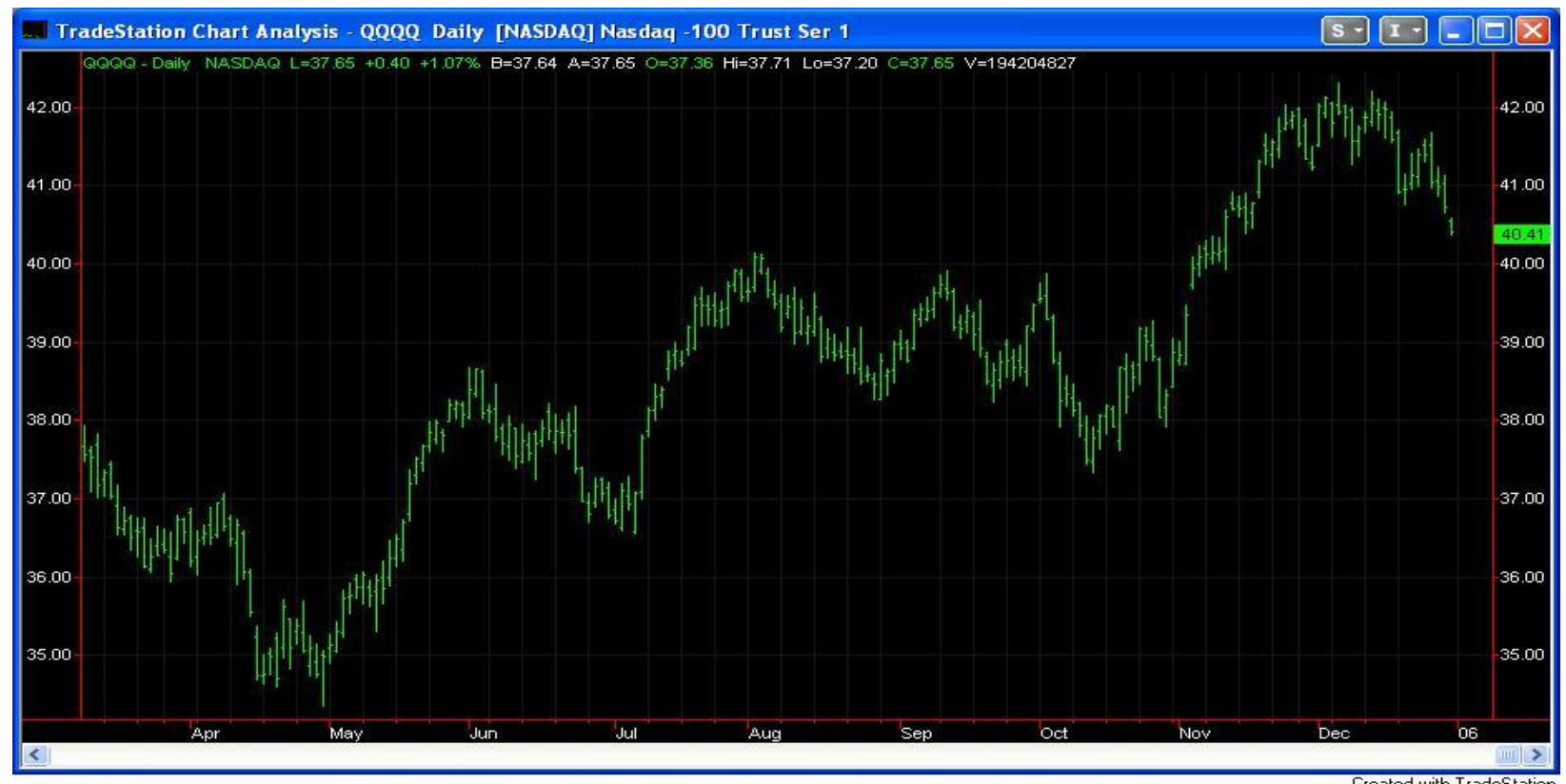

Created with TradeStation 
The simulations were done for the SPY and the QQQQ individually in each of the two time periods. Each strategy was individually programmed into TradeStation and executed automatically over each time period (i.e., consolidating and upward trending markets). TradeStation also allows the user to select a time chart on which to implement a strategy. The time charts used in the simulations were daily, 60 minute, 30 minute, 15 minute, 5 minute, and 1 minute. For each strategy, time period, and time chart TradeStation generates a report on the number of trades made and the profitability of these trades. It was from these reports that the profit, loss, and number of trades data reported below were gathered.

\section{THE RESULTS}

The simulation results for the SPY during the consolidating market period are shown in Table 1. Based on these results, the moving average trading system alone and this system using volume for confirmation each produced profit for only two time charts. For the moving average strategy these time charts were for the 30 minute and 15 minute charts. When volume confirmation was added to the moving average system, profits were produced for the time charts of 60 minutes and 15 minutes. However, the moving average system using the RSI as a confirming indicator produced profits on four time charts. These time charts were daily, 60 minutes, 30 minutes, and 1 minute. The results for the QQQQ during the consolidating market period are also shown in Table 1. On this asset, all three trading systems produced profit on four time charts. For both the moving average trading system and this system using volume as a confirming indicator, the profitable time charts were 60 minutes, 30 minutes, 15 minutes, and 1 minute. For the moving average system using the RSI as a confirming indicator, the profitable time charts were daily, 60 minute, 30 minute, and 1 minute charts.

Table 1

The Simulation Results: Consolidating Market (March 15, 1999-June 15, 1999)

SPY

\begin{tabular}{|c|c|c|c|c|c|c|}
\hline \multicolumn{3}{|c|}{ Moving Average } & \multicolumn{2}{c|}{ Moving Average with Volume } & \multicolumn{2}{c|}{ Moving Average with RSI } \\
\hline $\begin{array}{c}\text { Time } \\
\text { Frame }\end{array}$ & Profit (\$) & $\begin{array}{c}\text { Number of } \\
\text { Trades }\end{array}$ & Profit (\$) & Number of Trades & Profit (\$) & Number of Trades \\
\hline Daily & 0 & 0 & 0 & 0 & 138 & 1 \\
\hline 60 Minute & $(696)$ & 32 & 156 & 42 & 167 & 15 \\
\hline 30 Minute & 253 & 70 & $(430)$ & 84 & $(189)$ & 62 \\
\hline 15 Minute & 243 & 142 & 422 & 294 & $(738)$ & 123 \\
\hline 5 Minute & $(2104)$ & 483 & $(743)$ & 1421 & 1895 & 556 \\
\hline 1 Minute & $(4266)$ & 2414 & $(2810)$ & & & \\
\hline
\end{tabular}

QQQQ

\begin{tabular}{|c|c|c|c|c|c|c|}
\hline \multicolumn{3}{|c|}{ Moving Average } & \multicolumn{2}{c|}{ Moving Average with Volume } & \multicolumn{2}{c|}{ Moving Average with RSI } \\
\hline $\begin{array}{c}\text { Time } \\
\text { Frame }\end{array}$ & Profit (\$) & $\begin{array}{c}\text { Number of } \\
\text { Trades }\end{array}$ & Profit (\$) & Number of Trades & Profit (\$) & Number of Trades \\
\hline Daily & $(190)$ & 1 & $(190)$ & 1 & 94 & 1 \\
\hline 60 Minute & 902 & 26 & 198 & 13 & 199 & 15 \\
\hline 30 Minute & 552 & 60 & 221 & 77 & $(106)$ & 58 \\
\hline 15 Minute & 271 & 133 & 86 & 228 & $(30)$ & 156 \\
\hline 5 Minute & $(858)$ & 403 & $(725)$ & 1208 & 147 & 758 \\
\hline 1 Minute & 1022 & 2041 & 359 & & & \\
\hline
\end{tabular}

( ) contains negative values. 
Table 2 shows the profits and number of trades from these trading strategies for both the SPY and the QQQQ during the uptrending market period. For the moving average strategy applied to the SPY, profits were only realized on the 1 minute chart. When volume was added as a confirming indicator, none of the time charts produced profitable trades. On the other hand, the moving average system using the RSI as confirmation produced profits on four time charts. These time charts were 60 minute, 30 minute, 15 minute, and 1 minute. The simulation results for the same market period applied to the QQQQ are also shown in Table 2. The moving average trading system and this system using volume as a confirming indicator produced positive profits only on daily time charts. However, when the RSI is used with the moving average, five of the time charts showed profits from trading. Only on the 1 minute chart were profits not realized

Table 2

The Simulation Results: Upward Trending Market (January 1, 2005-December 30, 2005)

SPY

\begin{tabular}{|c|c|c|c|c|c|c|}
\hline \multicolumn{3}{|c|}{ Moving Average } & \multicolumn{2}{c|}{ Moving Average with Volume } & \multicolumn{2}{c|}{ Moving Average with RSI } \\
\hline $\begin{array}{c}\text { Time } \\
\text { Frame }\end{array}$ & Profit (\$) & $\begin{array}{c}\text { Number } \\
\text { of Trades }\end{array}$ & Profit (\$) & Number of Trades & Profit (\$) & Number of Trades \\
\hline Daily & $(252)$ & 18 & $(235)$ & 10 & $(562)$ & 7 \\
\hline 60 Minute & $(1230)$ & 143 & $(362)$ & 80 & 961 & 60 \\
\hline 30 Minute & $(1304)$ & 281 & $(1101)$ & 171 & 629 & 113 \\
\hline 15 Minute & $(604)$ & 558 & $(685)$ & 338 & 168 & 226 \\
\hline 5 Minute & $(749)$ & 1608 & $(22)$ & 946 & $(566)$ & 651 \\
\hline 1 Minute & 547 & 8209 & $(64)$ & 4817 & 2274 & 3389 \\
\hline
\end{tabular}

QQQQ

\begin{tabular}{|c|c|c|c|c|c|c|}
\hline \multicolumn{3}{|c|}{ Moving Average } & \multicolumn{2}{c|}{ Moving Average with Volume } & \multicolumn{2}{c|}{ Moving Average with RSI } \\
\hline $\begin{array}{c}\text { Time } \\
\text { Frame }\end{array}$ & Profit (\$) & $\begin{array}{c}\text { Number } \\
\text { of Trades }\end{array}$ & Profit (\$) & Number of Trades & Profit (\$) & Number of Trades \\
\hline Daily & 279 & 14 & 187 & 7 & 261 & 8 \\
\hline 60 Minute & $(460)$ & 138 & $(270)$ & 80 & 60 & 3 \\
\hline 30 Minute & $(226)$ & 261 & $(61)$ & 165 & 391 & 112 \\
\hline 15 Minute & $(265)$ & 529 & $(321)$ & 431 & 605 & 623 \\
\hline 5 Minute & $(351)$ & 1547 & $(584)$ & 911 & 120 & 3104 \\
\hline 1 Minute & $(683)$ & 7922 & $(637)$ & 4744 & $(14)$ & \\
\hline
\end{tabular}

( ) contains negative values.

\section{THE CONCLUSIONS}

In the consolidating market for the SPY, the most profit was realized by using the moving average strategy with the RSI as a confirming indicator trading on 1 minute charts. However, the number of trades required was significant which might well generate transaction costs offsetting most or all of the profits. This strategy also produced the most profit across four different time charts while the other two strategies each produced profit on only two time charts. The magnitudes of all the profits varied greatly across the time charts and strategies. Overall, it appears that the moving average with confirmation by the RSI is the best strategy to attempt to automate trading on daily, 60 minute, 30 minute, and possibly 1 minute charts. However, it should be noted that this strategy produced significantly fewer trades than the other strategies and hence fewer opportunities to create profit.

Examining the QQQQ, all three strategies produce profits on four different time charts. The greatest single profit was produced using the moving average with the RSI trading 60 minute charts, closely followed by the moving average trading 1 minute charts. However, the number of transactions in the latter might well produce prohibitively high transaction costs. Consistently higher profits were produced by the moving average strategy 
traded on 60 minute, 30 minute, and 15 minute charts. This strategy generated a significantly greater number of trades than the other strategies traded on the same time charts, which will partially offset the profit with higher transaction costs.

An interesting observation across the simulations in the consolidation time period is that adding the confirming indicator of volume or the RSI to the moving average reduced the number of trades made across all the time charts. In fact, for all but one time chart, confirmation using the RSI reduced the number of trades more than the use of volume as a confirming indicator. In other words, the confirming indicators reduced the number of trading opportunities and yet did not always reduce profit. What needs to be determined by future study is how profit net of transaction costs varies across these various strategies and time charts. Finally, the magnitude of the profits when trading the relatively stable SPY varied across the three strategies and various time charts. However, for the more volatile QQQQ the profits tended to be greater for the simple moving average strategy than the other strategies.

Examining the market time period in which both indexes were trending upwards indicates that the moving average strategy with confirmation by the RSI dominated the other two strategies in terms of profits. For the SPY, the moving average with volume confirmation produced no profits on any of the time charts. The moving average strategy without any confirmation produced a profit only when trading 1 minute charts. However, the number of transactions would probably produce prohibitively costly trading costs. The moving average with the RSI confirmation produced positive profits trading all time charts except the daily chart. Similar results were found when trading the relatively more volatile QQQQ. The moving average and the moving average with volume confirmation produced profits only when trading the daily charts. Using the moving average with the RSI confirmation, profits were produced for all time charts except the 1 minute chart. Furthermore, the use of confirming indicators with the moving average reduced the number of trading opportunities. Usually, the RSI reduced the number of trading opportunities compared to using volume as a confirming indicator. More importantly, the use of the confirming indicators tended to increase profit and reduce losses.

The ultimate question posed by this paper is can automated trading strategies be profitable? The simulations indicated that by carefully selecting strategies to match the asset being traded and the market conditions (i.e., consolidating or trending upward), profits can be produced using automated trading strategies. However, transaction costs were not considered. These costs might dramatically impact the net trading profits from these automated strategies. What also appears to be true is that automation enforces discipline in trading, which would tend to improve profit but also could slow the adjustments made to changing markets compared to a human trader. The impact of this on profits is generally unclear.

\section{DIRECTIONS FOR FUTURE RESEARCH}

Additional research in the area of automated trading needs to take several directions. First, building on this study it would be interesting to compare these automated strategies in a down trending market as well as uptrend and consolidating markets. Second, trading costs need to be included in the analysis to fully understand the efficacy of automated trading. Finally, more detailed analysis of the strategies, time chart traded, and their influence on the number of trades and net profit require study.

\section{ACKNOWLEDGEMENTS}

The authors gratefully acknowledge the financial support of the College of Business \& Economics Summer Research Grant Program. 


\section{REFERENCES}

1. Ash, David W. (2004). Empowering Automated Trading in Multi-Agent Environments, Computational Intelligence, 20, 4, 562-583.

2. Austin, Mark P., Bates, Graham, Dempster, Michael A. H., Leemans, Vasco, and Wiliams, Stacy N. (2004). Adaptive Systems for Foreign Exchange Trading, Quantitative Finance, 4, August, C37-C45.

3. Brennan, M. J. and Cao, H. H. (1996). Information, Trade, and Derivative Securities, Review of Finance, 9 , 163-208.

4. Carr, P. and Madan, D. (2001). Optimal Positioning in Derivative Securities, Quantitative Finance, 1, 1, 19-37.

5. Dempster, M. A. H. and Jones, C. M. (2001). A Real-Time Adaptive Trading System Using Gentic Programming, Quantitative Finance, 1, 4, 397-413.

6. Dodd, Randall (2005). Sources of Vulnerability in U.S. Financial Markets, in Financialization and the World Economy, Gerald Epstein, Ed., Edward Springer.

7. Geczy, Christopher C., Minton, Bernadette A., and Schrand, Catherine (2005). Taking a View: Corporate Speculation, Governance and Compensation, Working Paper, http://credit. Wharton.upenn.edu/faculty/Schrand/GMS071705.pdf, accessed 12/20/06.

8. Gencay, Ramazan (1998). Optimization of Technical Trading Strategies and the Profitability in Security Markets, Economic Letters, 59, 249-254.

9. Hentschel, Ludger and Kothari, S. P. (2001). Are Corporations Reducing or Taking Risks with Derivatives, Journal of Financial and Quantitative Analysis, 36, 1, 93-118.

10. Oberlechner, Thomas (2001). Importance of Technical and Fundamental Analysis in the European Foreign Exchange Market, International Journal of Finance \& Economics, 6, 1, 81-93.

11. Smithson, Charles and Simkins, Betty J. (2005). Does Risk Management Add Value? A Survey of the Evidence, Journal of Applied Corporate Finance, 17, 3, 8-17.

12. Subramanian, Harish, Ramamoorthy, Subramanian, Stone, Peter, and Kuipers, Benjamin (2006). Designing Safe, Profitable Automated Stock Trading Agents Using Evolutionary Algorithms, GECCO'06, July 8-12, 2006, Seattle, WA., 1777-1784. 


\section{NOTES}

